\title{
Experimental and Numerical Studies on Gas Production from Methane Hydrate in Porous Media by Depressurization in Pilot-Scale Hydrate Simulator
}

\author{
Gang Li, Bo Li, Xiao-Sen Li,* Yu Zhang, and Yi Wang \\ Key Laboratory of Renewable Energy and Gas Hydrate, Guangzhou Institute of Energy Conversion, Chinese Academy of Sciences, \\ Guangzhou 510640, China
}

\begin{abstract}
Dissociation processes of methane hydrate in porous media using the depressurization method are investigated by a combination of experimental observations and numerical simulations. In situ methane hydrate is synthesized in the Pilot-Scale Hydrate Simulator (PHS), a three-dimensional (3D) 117.8-L pressure vessel. During the experiment, constant-pressure depressurization method is used during the hydrate dissociation. A vertical well at the axis of the PHS is used as the production well. The initial hydrate and aqueous saturations before dissociation are $S_{\mathrm{H} 0}=27 \%$ and $S_{\mathrm{A} 0}=37 \%$ in volume, respectively. The hydrate dissociates continuously under depressurization and there is little hydrate remaining in the PHS. The hydrate dissociation is an analog of a moving boundary ablation process, and the hydrate dissociation interface separates the hydrate dissociated zone containing only gas and water from the undissociated zone containing the hydrate. The temperature increases in the hydrate dissociated zone near the boundaries, while that in the hydrate undissociated zone around the PHS center basically remains constant. The numerical results of the cumulative gas produced, the remaining hydrate in the deposit, and the temperature spatial distribution all agree well with the experiments, which completes the validation of the mathematical model and numerical codes employed in this study. The heat transfer from the surroundings is predominant in our experimental and numerical cases. The analysis of sensitivity to the intrinsic permeability and the initial hydrate saturation of the numerical simulation are investigated.
\end{abstract}

\section{INTRODUCTION}

Natural gas hydrates (NGH) are solid, nonstoichiometric compounds formed by host water molecules with small guest molecules, such as $\mathrm{CH}_{4}, \mathrm{C}_{2} \mathrm{H}_{6}, \mathrm{C}_{3} \mathrm{H}_{8}, \mathrm{CO}_{2}, \mathrm{H}_{2} \mathrm{~S}$, etc. ${ }^{1}$ Natural gas hydrate deposits involve mainly $\mathrm{CH}_{4}$, and occur in the permafrost and in deep ocean sediment, where the necessary conditions of low temperature and high pressure exist for hydrate stability. NGH is buried in deep marine sediments or permafrost regions and has been recognized as a potential future energy resource. ${ }^{2-5}$

There are several methods for gas production from the hydrate deposit: (1) depressurization, ${ }^{6-10}$ to decrease the deposit pressure below the hydrate dissociation pressure at a specified temperature; (2) thermal stimulation, ${ }^{11-14}$ involving raising the deposit temperature above the dissociation temperature at a given pressure of the hydrate with the hot water, hot brine, or steam injection; (3) thermodynamic inhibitor effects, ${ }^{15-17}$ based on the use of chemicals, such as salts and alcohols to shift the hydrate pressure-temperature equilibrium conditions; (4) a combination of these methods. ${ }^{18-20}$ Earlier studies $^{3,20}$ indicate that depressurization is the simplest and most promising hydrate dissociation method, and possibly the only practical option in the majority of hydrate deposits, because of its technical and economic effectiveness, the fast response of hydrates to the rapidly propagating pressure wave, ${ }^{9}$ the near-incompressibility of water, and the large heat capacity of water.

Extensive reviews of research on hydrates were reported by Makogon, ${ }^{21}$ Sloan, ${ }^{1}$ and Moridis. ${ }^{3,4}$ Thermodynamic modeling of the hydrate decomposition process by depressurization has been studied by a number of authors. Holder et al. ${ }^{6}$ first reported a three-dimensional (3D) finite-difference numerical simulation of heat and mass transfer in a reservoir containing layers of gas hydrates and free natural gas and the depressurization process of this hydrate reservoir. They considered the variation of temperature during hydrate decomposition, and the temperature distribution in the natural gas layer was evaluated assuming a conduction heat transfer process. Burshears et al. ${ }^{22}$ extended the model of Holder et al. ${ }^{6}$ and considered the influence of water transport in the layer. They concluded that the gas production by depressurization could be sustained with the supply of heat from the hydrate reservoir environment. Yousif et al. ${ }^{7}$ developed a onedimensional (1D) apparatus and a three-phase 1D model to simulate the process of gas production from Berea sandstone samples containing methane hydrate by means of a depressurization mechanism, and they treated the depressurization process as a Kim-Bishnoi ${ }^{23}$ dynamic isothermal process. Gas and water flows were included in this 1D model. The model closely matched the experimental data of gas and water production, the progress of the dissociation front, and the pressure and saturation profiles.

In recent years, mathematical models used to describe the dissociation process in hydrate bearing porous media are developed using the simple Stefan's equations. ${ }^{21,24-27}$ Makogon $^{21}$ described the process of hydrate decomposition with an

Received: July 23, 2012

Revised: September 21, 2012

Published: September 26, 2012 
Cold Room

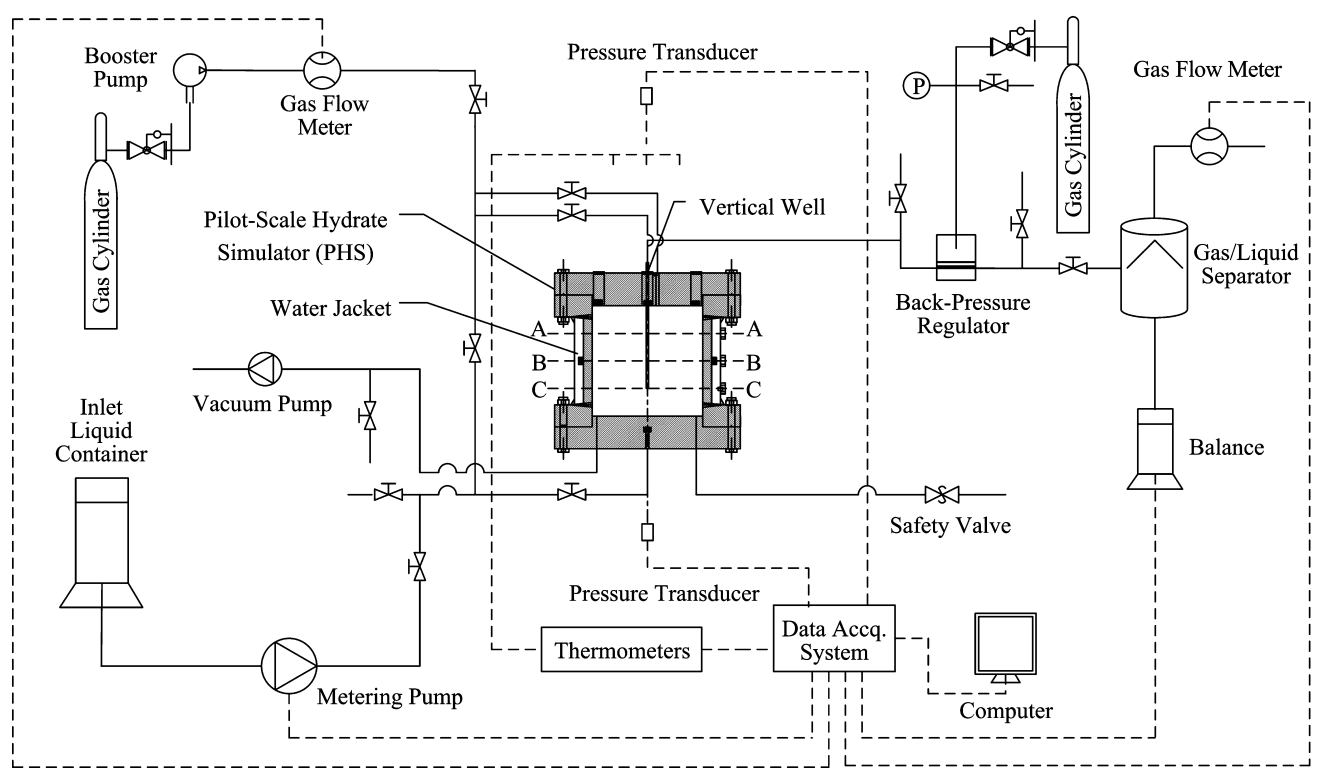

Figure 1. Schematic of the experimental apparatus.

analog of a moving boundary ablation process. Conductiveconvective heat transfer, as well as the effect of the throttling process, was included in the energy equation. Neglecting the effect of the release of water, a self-similar solution for the pressure distributions in the hydrate reservoir was obtained and analytical expressions for the temperature and pressure profiles for the linearized system of equations for both $1 \mathrm{D}$ and cylindrical models were reported. Tsypkin ${ }^{24}$ extended the model by including the effect of water movement in a $1 D$ model. Similarity solutions for temperature and pressure distributions were also obtained using a perturbation method. Ahmadi et al. ${ }^{25,26}$ and Ji et al. ${ }^{27}$ reported numerical results for the $1 \mathrm{D}$ model described by Makogon ${ }^{13}$ and made a series of sensitivity analyses of natural gas production as variations of reservoir parameters. Sun et al. ${ }^{28}$ developed a thermal, threephase, 1D numerical model to simulate two regimes of gas production from sediments containing methane hydrates by depressurization: the dissociation-controlled regime and the flow-controlled regime. A dimensionless parameter, namely, dissociation-flow time-scale ratio, was defined and employed to identify the two regimes. This model showed that laboratoryscale experiments are often dissociation-controlled, but the field-scale processes are typically flow-controlled. Song et al. ${ }^{13}$ developed a two-dimensional (2D) axisymmetric simulator for gas production from hydrate reservoirs and simulated the process of laboratory-scale hydrate decomposition by depressurization and found the high surrounding temperature and low outlet valve pressure may increase the rate of hydrate dissociation.

Experimental investigations into the hydrate production behaviors by depressurization were carried out using the $1 \mathrm{D}$ or $2 \mathrm{D}$ experimental apparatuses. ${ }^{29-32}$ Lee et al. ${ }^{29}$ designed an experimental apparatus to analyze the dissociating phenomena of the hydrate in the porous rock using the depressurization method. The experimental results presented the comparison of gas productivities and propagations of dissociation front during the depressurization process and indicated that the degree of depressurization was a significant factor influencing the gas production rate. Tang et al. ${ }^{30}$ carried out the experimental work on the methane gas production from an experimental-scale hydrate reservoir by depressurization. The results suggested that the hydrate dissociation kinetics had a great effect on the gas production behavior for the laboratory-scale hydratebearing core. Oyama et al. $^{31}$ reported an experimental study of an artificial sedimentary core on gas production to clarify the dissociation characteristics during depressurization under various production pressure conditions. A numerical model expressed as a function of heat transfer and mass transfer was developed for methane hydrate dissociation process in the porous media. The experimental and numerical simulation results indicated that the heat transfer from the surroundings was predominant in their experimental case. Haligva et al. ${ }^{32}$ reported the recovery of methane from hydrate by depressurization using three different sized beds of silica sand particles. The experimental results indicated that the initial rate of gas recovery was strongly dependent on the silica sand bed size, and the rate of recovery depended weakly on the size during the second stage.

To investigate the gas production characteristics in a $3 \mathrm{D}$ reservoir, it is very important to simulate the hydrate dissociation behaviors in the $3 \mathrm{D}$ experimental apparatus. However, so far, there are few reports on this aspect. Zhou et al. ${ }^{33}$ developed a cylindrical reactor, a $72 \mathrm{~L}$ large-scale reactor vessel and investigated the gas production from methane hydrate. A cooling effect was observed during the dissociation via depressurization experiments, caused by the endothermic dissociation reaction. The results confirmed that the hydrate formation occurred not only just at the top of the sediment but also at various locations.

Recently, we have reported the investigation into the gas production behavior from methane hydrate in the porous sediment in a 3D cubic hydrate simulator (CHS) with the effective volume of $5.8 \mathrm{~L}$ using both the huff and puff ${ }^{19,34}$ and the depressurization ${ }^{35}$ methods. With the temperature, pressure, and resistance changes at different locations in this 3D hydrate reservoir, the kinetic characteristics in the dissociation process were studied. The experimental results by depressurization show that the gas production process 


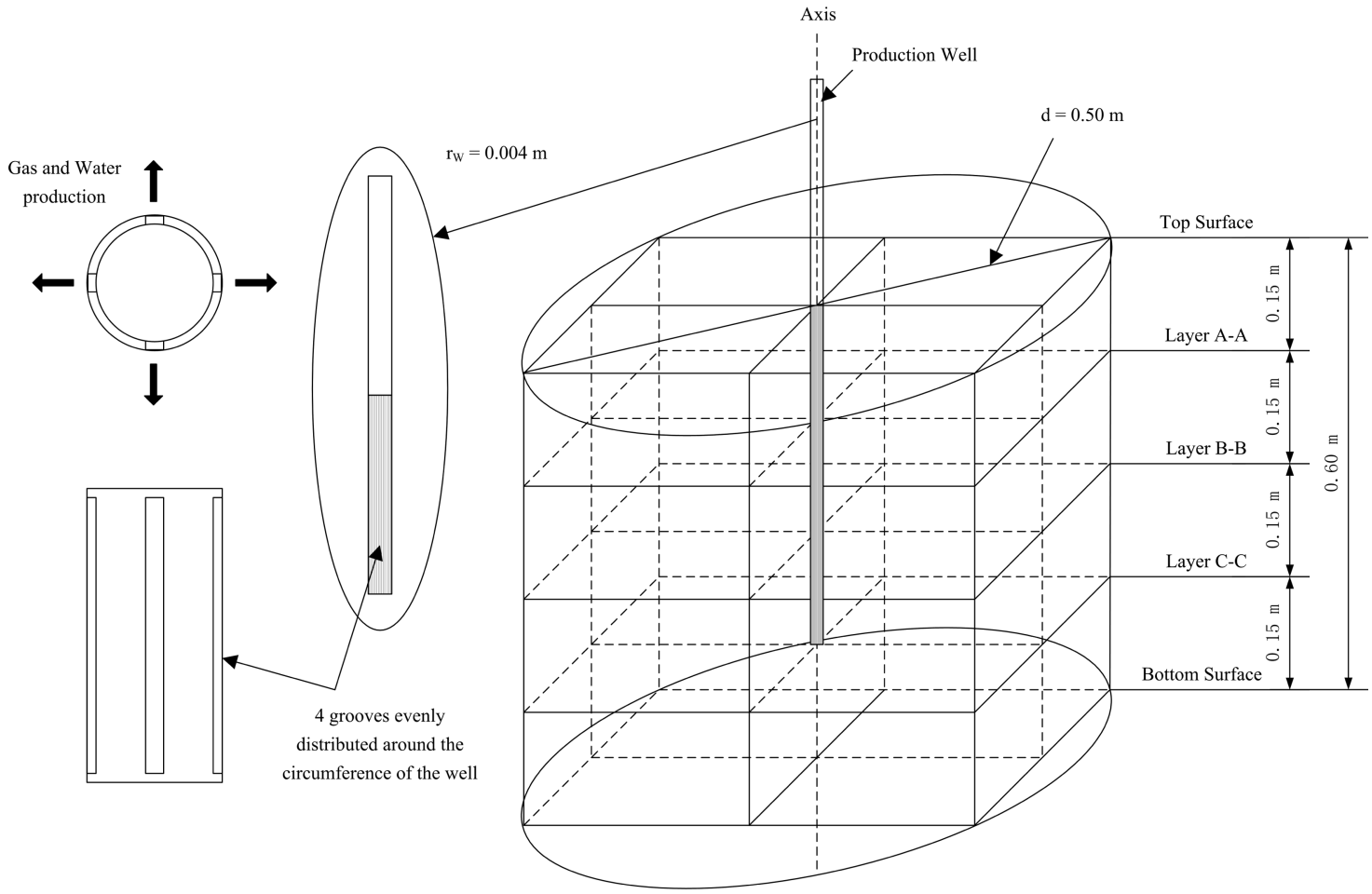

Figure 2. Schematic of the layers and the well design of the PHS.

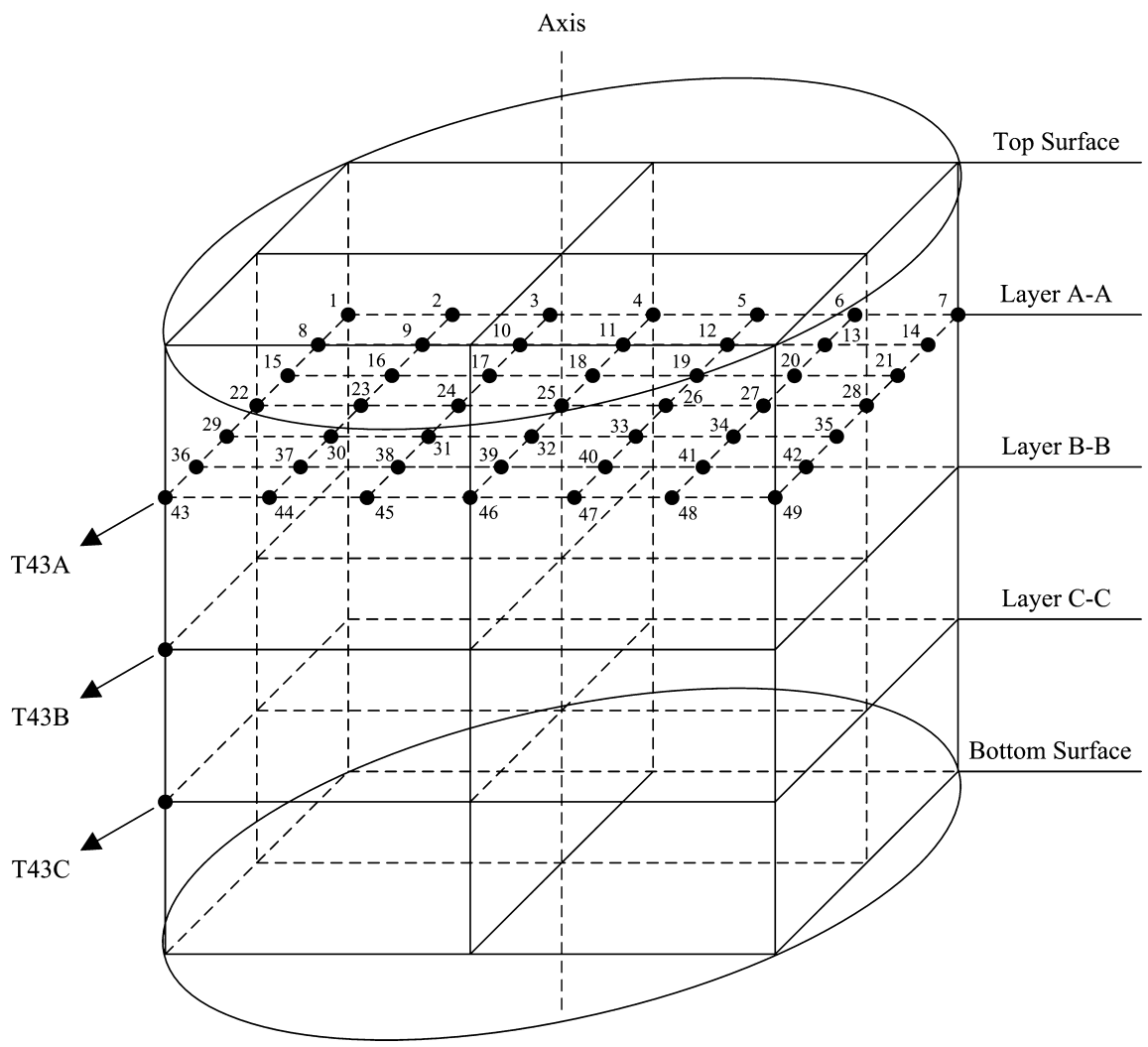

Figure 3. Schematic of the distributions of the thermometers in the PHS.

consists of three periods: the free gas production, mixed gas (free gas and gas dissociated from the hydrate) production, and gas production from the hydrate dissociation. Furthermore, the Pilot-Scale Hydrate Simulator (PHS), a novel 3D 117.8-L pressure vessel, has been developed for the gas production from the methane hydrate in the sediment by using the huff and puff method. ${ }^{36}$

The primary objective of the present study was to investigate the gas production behavior from a methane hydrate reservoir in unconsolidated sediment using depressurization method by a 
combination of experimental observations in the PHS and numerical simulations using the TOUGH+HYDRATE code. A vertical well at the axis of the PHS was used as the production well. With the temperature and pressure at different locations in the 3D hydrate reservoir, the kinetic characteristics in the dissociation process of the methane hydrate under depressurization were studied. In addition, the production of gas and water under depressurization was monitored in the PHS.

\section{EXPERIMENTS}

2.1. Apparatus. The schematic of the experimental apparatus used in this work is shown in Figure 1. The PHS, withstanding pressures of up to $30 \mathrm{MPa}$, is made of stainless steel. The low temperatures required for hydrate formation and dissociation are achieved by placing the whole apparatus inside a walk-in cold room, and there is a water jacket around the PHS. A safety valve and a vacuum pump are connected to the PHS. The thermometers are Pt100 with the range of -20 to $200{ }^{\circ} \mathrm{C}, \pm 0.1{ }^{\circ} \mathrm{C}$. A pressure transducer, TRAGAG NAT $8251.84 .2517,0-40 \mathrm{MPa}, \pm 0.1 \%$, is used to measure the system pressure. Two gas flow meters, which are used to measure the cumulative gas injected into the PHS, the gas production rate and the cumulative gas produced from the vessel, are both of D07-11CM, 0$10 \mathrm{~L} / \mathrm{min}, \pm 2 \%$ from the Seven Star Company. The thermometers, pressure transducer, and gas flow meters are calibrated using a mercury thermometer with the tolerance of $\pm 0.01{ }^{\circ} \mathrm{C}$, a pressure test gauge with the error of $\pm 0.05 \%$, and a wet gas meter with the accuracy of $\pm 10 \mathrm{~mL} / \mathrm{min}$, respectively. A metering pump Beijing Chuangxintongheng HPLC P6000 with the range $250 \mathrm{~mL} / \mathrm{min}$ can withstand pressures of up to $15 \mathrm{MPa}$. An inlet liquid container with the inner volume of $10 \mathrm{~L}$ is used to contain the deionized water used in the experiment. A back-pressure regulator (the pressure range of 0 to 30 $\mathrm{MPa}, \pm 0.02 \mathrm{MPa}$ ) connected to the outlet of the PHS is used to control the gas production pressure. A gas cylinder is used to provide the driving force of the back-pressure regulator. A balance, used to measure the mass of liquid produced from the PHS, is Sartorius BS $2202 \mathrm{~S}, 0-2200 \mathrm{~g}, \pm 0.01 \mathrm{~g}$. The data acquisition system records the temperature, the pressure, the cumulative gas produced from the vessel, the gas production rate, and the liquid production rate. The liquid injection rate can be controlled by the metering pump, which is connected to the data acquisition system. In this work, methane gas with a purity of $99.99 \%$ is used.

Figure 2 shows the schematic of the layers and the well design of the PHS. The PHS is a cylindrical pressure vessel $(0.60 \mathrm{~m}$ in height, $0.50 \mathrm{~m}$ in diameter) with the inner volume of $117.8 \mathrm{~L}$. As shown in Figures 1 and 2, there are three horizontal layers named $\mathrm{A}-\mathrm{A}, \mathrm{B}-\mathrm{B}$, and $\mathrm{C}-\mathrm{C}$ inside the vessel, which equally divide the cubic vessel into 4 regions. The distance between the layer $\mathrm{A}-\mathrm{A}$ and layer $\mathrm{B}-\mathrm{B}$ is $0.15 \mathrm{~m}$, a quarter of the internal length of the PHS, which is the same with that between the layer $\mathrm{B}-\mathrm{B}$ and layer $\mathrm{C}-\mathrm{C}$, while the layer $\mathrm{B}-\mathrm{B}$ is in the middle of the PHS. The top surface and the bottom surface are both the internal surfaces of the PHS. The production well, with the radius of $r_{\mathrm{W}}=0.004 \mathrm{~m}$, is at the axis of the PHS. There are four grooves evenly distributed along the circumference of the vertical well, and they are extended from the top surface of the PHS to layer C-C. The gas and water production from the PHS are both through the grooves shown in Figure 2.

Figure 3 shows the schematic of the distribution of the thermometers (the temperature measuring spots) in the PHS. There are 49 thermometers evenly distributed on each layer, with a total of 147 spots in the PHS. In other words, on each layer (layers A-A, B$\mathrm{B}$, and $\mathrm{C}-\mathrm{C})$, there is a 49 -spot distribution of the thermometers (T1-T49), with T25 at the center and T1, T7, T43, and T49 at the corners. The thermometers at the same spots are distinguished by the different layers, for example, as shown in Figure 3, the 43rd thermometer on layer $\mathrm{A}-\mathrm{A}$ is called $\mathrm{T} 43 \mathrm{~A}$, and those on layer $\mathrm{B}-\mathrm{B}$ and layer $\mathrm{C}-\mathrm{C}$ are $\mathrm{T} 43 \mathrm{~B}$ and $\mathrm{T} 43 \mathrm{C}$, respectively.

2.2. Procedure. Table 1 shows the experimental conditions and results of hydrate formation and dissociation. During the experiment, the raw dry quartz sand with grain sizes between 300 and $450 \mu \mathrm{m}$ was
Table 1. Experimental Conditions and Results of Hydrate Formation and Dissociation

\begin{tabular}{|c|c|}
\hline parameter & value \\
\hline height of the PHS $\Delta Z$ & $0.60 \mathrm{~m}$ \\
\hline diam. of the PHS $\Delta R$ & $0.50 \mathrm{~m}$ \\
\hline vol. of the PHS & $117.8 \mathrm{~L}$ \\
\hline porosity $\phi$ & 0.435 \\
\hline quartz sand density $\rho_{\mathrm{R}}$ & $2600 \mathrm{~kg} / \mathrm{m}^{3}$ \\
\hline gas composition & $100 \% \mathrm{CH}_{4}$ \\
\hline water salinity & 0 \\
\hline initial temp. before (hydrate) formation & $14.29{ }^{\circ} \mathrm{C}$ \\
\hline initial pressure before formation & $19.56 \mathrm{MPa}$ \\
\hline molar vol. of gas before formation & $\begin{array}{l}9.50 \times 10^{-5} \mathrm{~m}^{3} / \mathrm{mol}(\text { Peng- } \\
\text { Robinson equation) }\end{array}$ \\
\hline total vol. of gas before formation & $\begin{array}{l}20.02 \mathrm{~L}(4720 \mathrm{~L} \text { in standard } \\
\text { state })\end{array}$ \\
\hline total vol. of water before formation & $31.33 \mathrm{~L}$ \\
\hline time point after formation & $t=-52 \min ($ Figure 5$)$ \\
\hline final temp. after formation & $8.67{ }^{\circ} \mathrm{C}$ \\
\hline final pressure after formation & $8.27 \mathrm{MPa}$ \\
\hline molar vol. of gas after formation & $\begin{array}{l}2.30 \times 10^{-4} \mathrm{~m}^{3} / \mathrm{mol}(\text { Peng- } \\
\text { Robinson equation) }\end{array}$ \\
\hline total vol. of gas after formation & $\begin{array}{l}16.77 \mathrm{~L}(1,630 \mathrm{~L} \text { in standard } \\
\text { state })\end{array}$ \\
\hline total vol. of water after formation & $17.05 \mathrm{~L}$ \\
\hline total vol. of hydrate after formation & $17.54 \mathrm{~L}$ \\
\hline $\begin{array}{l}\text { time point after free gas release (before } \\
\text { hydrate dissociation) }\end{array}$ & $t=0 \mathrm{~min}$ (Figure 5$)$ \\
\hline $\begin{array}{l}\text { final temp. after free gas release (initial temp. } \\
\text { before hydrate dissociation } T_{0} \text { ) }\end{array}$ & $5.88^{\circ} \mathrm{C}$ \\
\hline final pressure after free gas release & $4.76 \mathrm{MPa}$ \\
\hline molar vol. of gas after free gas release & $\begin{array}{l}4.28 \times 10^{-4} \mathrm{~m}^{3} / \mathrm{mol}(\text { Peng- } \\
\text { Robinson equation) }\end{array}$ \\
\hline total vol. of gas after free gas release & $\begin{array}{l}18.51 \mathrm{~L}(969 \mathrm{~L} \text { in standard } \\
\text { state) }\end{array}$ \\
\hline total vol. of water after free gas release & $19.01 \mathrm{~L}$ \\
\hline total vol. of hydrate after free gas release & $13.85 \mathrm{~L}$ \\
\hline avg. system pressure during dissociation $P$ & $4.68 \mathrm{MPa}$ \\
\hline initial saturations before dissociation & $S_{\mathrm{H} 0}=27 \%, S_{\mathrm{A} 0}=37 \%$ \\
\hline
\end{tabular}

tightly packed in the vessel, and then, the vessel was evacuated twice to remove air in it with a vacuum pump. The quartz sand in the vessel was wetted to saturation with distilled water at atmospheric pressure using a metering pump. The sand sediment as the porous media was considered as saturation when the amount of water produced from the vessel was equal to the amount of water injected. Using the fugacity model of Li et al., ${ }^{37}$ the equilibrium hydrate dissociation pressure in the sediment at the working temperature of $8.67{ }^{\circ} \mathrm{C}$ was calculated, and the calculated value was $6.07 \mathrm{MPa}$. Then, the methane gas was injected into the vessel until the system pressure in the vessel reached approximately $20 \mathrm{MPa}$, which was much higher than the equilibrium hydrate dissociation pressure at the working temperature. After that, the vessel was closed as an isochoric system. The temperature was gradually decreased to form the hydrate by changing the water bath temperature. The hydrate formation process lasted for about 32 days, and then, the system pressure decreased to $8.27 \mathrm{MPa}$.

Depressurization is considered to be a promising technique of producing gas from methane hydrate reservoirs. The following procedure was used to investigate into the dissociation characteristics of methane hydrate using the depressurization method. The backpressure regulator was used to release the free gas and water from the vessel and the system pressure gradually decreased from $t=-52 \mathrm{~min}$ to $t=0 \mathrm{~min}$. When the system pressure decreased to approximately 4.76 $\mathrm{MPa}$, the experimental and numerical simulation began $(t=0$ $\min$ ), and the initial temperature before dissociation $T_{0}=5.88{ }^{\circ} \mathrm{C}$ Subsequently, the hydrate began to dissociate, and the gas and water were produced from the vessel through the production well. 
The volume of the water and gas before hydrate formation is equal to the total volume of water, gas, and hydrate after hydrate formation:

$$
V_{\mathrm{w} 1}+V_{\mathrm{g} 1}=V_{\mathrm{w} 2}+V_{\mathrm{g} 2}+V_{\mathrm{h} 2}
$$

where $V_{\mathrm{w} 1}$ and $V_{\mathrm{g} 1}$ are the volume of water and gas before hydrate formation, respectively. $V_{\mathrm{w} 2}, V_{\mathrm{g} 2}$, and $V_{\mathrm{h} 2}$ are the volume of water, gas, and hydrate after hydrate formation.

It was assumed that there is $5.75 \mathrm{~mol}$ water in $1 \mathrm{~mol}$ methane hydrate, the density of methane hydrate is $0.94 \mathrm{~g} / \mathrm{cm}^{3}$, and water in the vessel is incompressible. At $t=0 \mathrm{~min}$, the initial saturations of hydrate and aqueous $\left(S_{\mathrm{H} 0}=27 \%\right.$ and $S_{\mathrm{A} 0}=37 \%$ in volume) before hydrate dissociation were determined through pressure and temperature measurements and mass balance calculations using the PengRobinson equation. When there was little gas release, it was considered as the end of the gas production process $(t=7014 \mathrm{~min})$. During the hydrate dissociation, the temperatures and the pressure in the vessel and the gas and water production rates were recorded at $20 \mathrm{~s}$ intervals.

\section{NUMERICAL SIMULATIONS}

3.1. Numerical Simulation Code. For this numerical simulation study, we used both the serial and parallel versions of the TOUGH+HYDRATE code. ${ }^{38,39}$ The model accounts for heat and four mass components (i.e., water, $\mathrm{CH}_{4}$, hydrate, and water-soluble inhibitors such as salts or alcohols) that are partitioned among four possible phases: gas, aqueous liquid, ice, and hydrate. A total of 15 states (phase combinations) can be described by the code, which can handle any combination of hydrate dissociation mechanisms and can describe the phase changes and steep solution surfaces typical of hydrate problems. In this code, the impact of the movement and the volume expansion of the sediments are neglected.

3.2. Domain Discretization. Figure 4 shows the grid used in the numerical simulations. The cylindrical domain of the PHS in Figure 2 is discretized into $47 \times 102=4794$ gridblocks in $(r, z)$, of which 4601 are active (the remaining being boundary cells corresponding to the constant $P$ and $T$ conditions). Assuming an equilibrium reaction of hydrate dissociation, ${ }^{38,40}$ this grid results in 14382 coupled equations that are solved simultaneously. Discretization along the radial direction is nonuniform (with $\Delta r$ increasing from 0.002 to $0.007 \mathrm{~m}$ ), increasing from $r_{\mathrm{W}}=0.004 \mathrm{~m}$ to $r_{\max }=0.257 \mathrm{~m}$. Discretization along the $z$-axis is uniform (with $\Delta z=0.006 \mathrm{~m}$ ) within the PHS. The uppermost and lowermost layers $(z>0.30$ $\mathrm{m}$ and $z<-0.30 \mathrm{~m}$, respectively) are the top and bottom boundaries of stainless steel with the thickness of $\Delta z=0.007$ $\mathrm{m}$. The grids of $r>0.25 \mathrm{~m}$ are the cylindrical boundaries with the thickness of $\Delta r=0.007 \mathrm{~m}$. Based on the experiment, the perforated interval of the production well (with the radius of $r_{\mathrm{W}}$ $=0.004 \mathrm{~m}$ ) at the axis of the PHS, is extended from the top surface to the layer $\mathrm{C}-\mathrm{C}$.

3.3. System Properties. The system properties and conditions of the hydrate deposit that are used in the numerical simulation are shown in Table 2. Based on the direct measurements during the experiment, the system pressure during dissociation $P$, initial temperature $T_{0}$ before hydrate dissociation, gas composition, water salinity, porosity $\phi$, and quartz sand density $\rho_{\mathrm{R}}$ are shown in Table 2 . According to the calculations based on the experimental results, in the numerical simulation, the initial hydrate and aqueous saturations before hydrate dissociation are set to be $S_{\mathrm{H} 0}=27 \%$ and $S_{\mathrm{A} 0}=37 \%$ in volume, respectively.

The estimates of the intrinsic permeability $k$ and the wettability properties (capillary pressure and relative permeabilities, with all related parameters) in Table 2, are based on

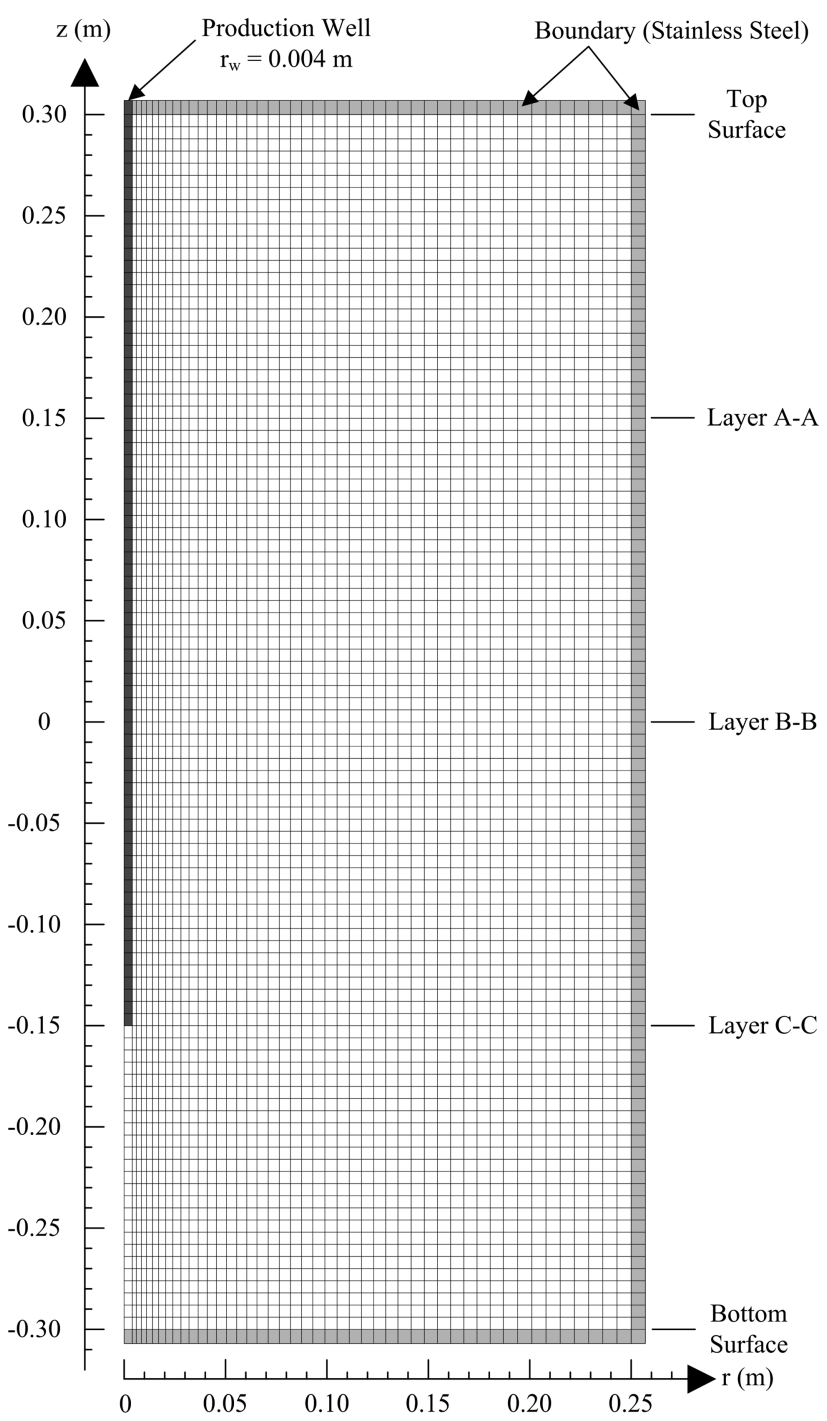

Figure 4. Grid used in the numerical simulations.

Table 2. Properties and Conditions of the Hydrate Deposit in the Numerical Simulation

\begin{tabular}{|c|c|}
\hline parameter & value \\
\hline $\begin{array}{l}\text { intrinsic permeability } \\
k_{\mathrm{r}}=k_{z}\end{array}$ & $3.0 \times 10^{-12} \mathrm{~m}^{2}(=3.0$ Darcies $)$ \\
\hline $\begin{array}{l}\text { dry thermal } \\
\text { conductivity } k_{\Theta R D}\end{array}$ & $1.0 \mathrm{~W} /(\mathrm{m} \cdot \mathrm{K})$ \\
\hline $\begin{array}{l}\text { wet thermal } \\
\text { conductivity } k_{\Theta \mathrm{RW}}\end{array}$ & $3.1 \mathrm{~W} /(\mathrm{m} \cdot \mathrm{K})$ \\
\hline $\begin{array}{l}\text { composite thermal } \\
\text { conductivity } \\
\text { model }^{38,42}\end{array}$ & $k_{\Theta \mathrm{C}}=k_{\Theta \mathrm{RD}}+\left(S_{\mathrm{A}}^{1 / 2}+S_{\mathrm{H}}^{1 / 2}\right)\left(k_{\Theta \mathrm{R} W}-k_{\Theta \mathrm{RD}}\right)+\phi S_{\mathrm{I}} k_{\Theta 1}$ \\
\hline $\begin{array}{l}\text { capillary pressure } \\
\text { model }^{l 33}\end{array}$ & $\begin{array}{l}P_{\text {cap }}=-P_{01}\left[\left(S^{*}\right)^{-1 / \lambda}-1\right]^{1-\lambda} \\
S^{*}=\left(S_{\mathrm{A}}-S_{\mathrm{irA}}\right) /\left(1-S_{\mathrm{irA}}\right)\end{array}$ \\
\hline$S_{\mathrm{irA}}$ & 0.19 \\
\hline$\lambda$ & 0.45 \\
\hline$P_{01}$ & $10^{5} \mathrm{~Pa}$ \\
\hline $\begin{array}{l}\text { relative permeability } \\
\text { model }^{38}\end{array}$ & $\begin{array}{l}k_{\mathrm{rA}}=\left(\mathrm{S}_{\mathrm{A}}^{*}\right)^{n}, k_{\mathrm{rG}}=\left(\mathrm{S}_{\mathrm{G}} *\right)^{n \mathrm{G}} \\
S_{\mathrm{A}}^{*}=\left(S_{\mathrm{A}}-S_{\mathrm{irA}}\right) /\left(1-S_{\mathrm{irA}}\right) \\
S_{\mathrm{G}} *=\left(S_{\mathrm{G}}-S_{\mathrm{irG}}\right) /\left(1-S_{\mathrm{irA}}\right)\end{array}$ \\
\hline$n$ & 3.572 \\
\hline$n_{\mathrm{G}}$ & 3.572 \\
\hline$S_{\text {irG }}$ & 0.394 \\
\hline$S_{\text {irA }}$ & 0.20 \\
\hline
\end{tabular}


the porous media (quartz sand with a size range of 300-450 $\mu \mathrm{m})$ used in this simulation.

The wellbore is simulated as a pseudoporous medium with $\phi$ $=1.0, k=5.0 \times 10^{-9} \mathrm{~m}^{2}$ (5000 Darcies), a capillary pressure $P_{\text {cap }}=0$, and aqueous and gas relative permeabilities $\left(k_{\mathrm{rA}}\right.$ and $\left.k_{\mathrm{rG}}\right)$ as linear functions of the aqueous and gas phase saturations $\left(S_{\mathrm{A}}\right.$ and $\left.S_{\mathrm{G}}\right)$, respectively.

\section{RESULTS AND DISCUSSION}

4.1. Pressure and Boundary Temperature. Figure 5 shows the system pressure $P$ and the temperature of boundaries $T_{\text {bon }}$ profiles of experimental results during hydrate dissociation in the PHS. Due to the high porosity and permeability of the sediment, the pressures at the different measuring points in the PHS have little discrepancy. Thus, the pressure at any point in the PHS can be taken as the system pressure.

The pressure $P$ remains constant during the hydrate dissociation using the constant-pressure depressurization method (after $t=0 \mathrm{~min}$ ), with the average value of approximately $4.68 \mathrm{MPa}$, and is controlled by the back-pressure regulator in Figure 1. During the experiment, the temperature of the stainless steel boundaries $T_{\text {bon }}$ (Figure 5) increases obviously over time from approximately 5.69 to $8.45{ }^{\circ} \mathrm{C}$. $T_{\text {bon }}$ are $5.98,6.71,7.09$, and $7.98{ }^{\circ} \mathrm{C}$ at $t=0,2500,3500$, and 5500 min, respectively.

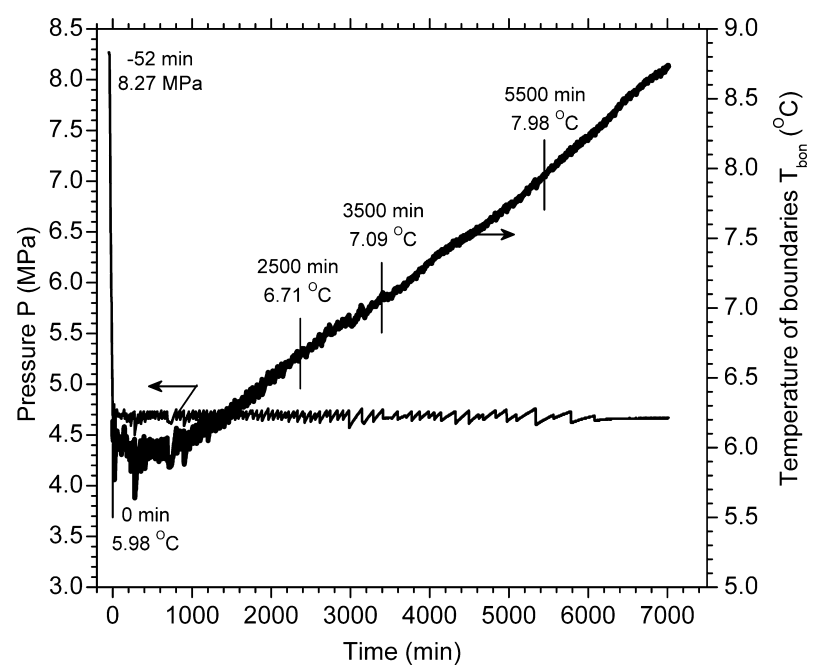

Figure 5. System pressure $P$ and the temperature of boundaries $T_{\text {bon }}$ profiles of experimental results during hydrate dissociation in the PHS.

4.2. Gas and Water Production. Figures 6-8 show the comparisons of the cumulative gas and water produced and the remaining mass of hydrate in the deposit over time of experimental and numerical simulation results during hydrate dissociation in the PHS under depressurization condition. Both the experimental and numerical simulation results in Figures 6-8 indicate that (i) the hydrate in the PHS dissociates continuously until the end of the production process; (ii) the gas and water production rates and the hydrate dissociation rate decrease over time while using the constant-pressure depressurization method; (iii) there is little hydrate remaining in the PHS (more than 99\% hydrate dissociates) after about $t=$ $6000 \mathrm{~min}$. Of those, (i) is caused by the depressurization effect and the continuous heat transfer from the boundaries of the PHS; the reasons for (ii) are the continuous decrease of the hydrate dissociation interface over time and the increase of the

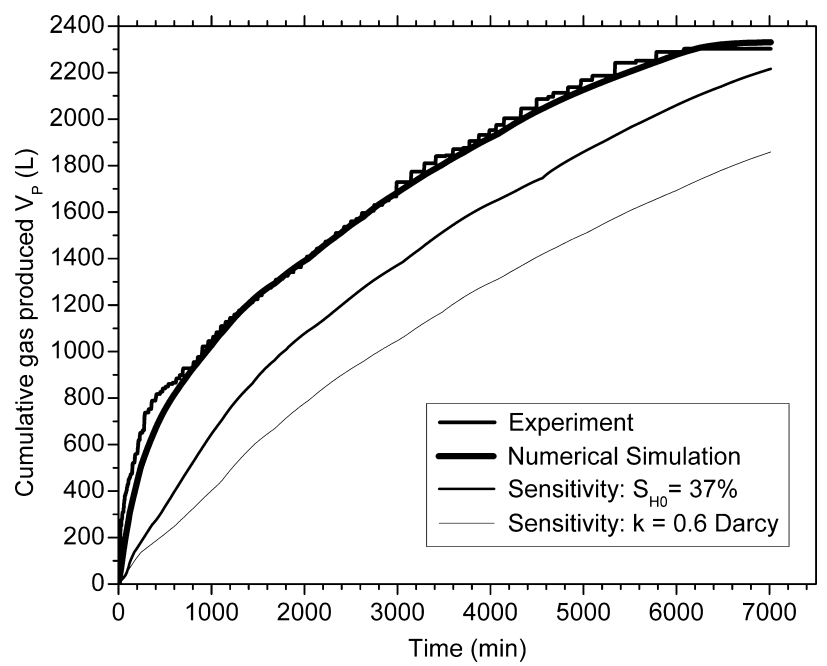

Figure 6. Comparison of $V_{\mathrm{P}}$ of experimental and numerical simulation results during hydrate dissociation in the PHS, and its sensitivities to $S_{\mathrm{H} 0}$ and $k$ of the numerical simulation.

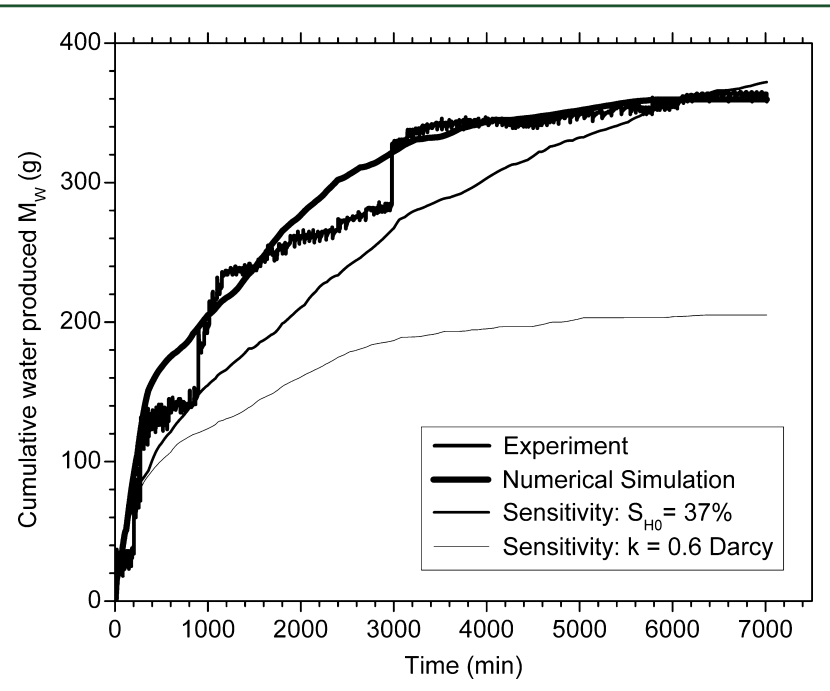

Figure 7. Comparison of $M_{\mathrm{W}}$ of experimental and numerical simulation results during hydrate dissociation in the PHS and its sensitivities to $S_{\mathrm{H} 0}$ and $k$ of the numerical simulation.

distance between the boundary and the hydrate dissociation interface, which caused the decrease of the heat transfer efficiency; (iii) indicates that almost all the hydrate in the PHS could dissociate using single depressurization method. Figure 7 shows the discontinuity of the water production process in the experiment. The gas and water in the vessel move from the surroundings toward the production well simultaneously. The water first fills the pores in the near-well region and accumulates around the well. During the experiment, when the aqueous saturation increased to a certain value, the water is removed out from the production well under the effect of the pressure discrepancy between the pressure in the vessel and the production pressure controlled by the back-pressure regulator.

4.3. Spatial Distribution of $T$. Figure 9 shows the evolutions of the temperature spatial distributions over time of experimental and numerical simulation results during hydrate dissociation in the PHS. The temperature measuring spots of T7A, T7B, T7C, ..., T25A, T25B, T25C, ..., T43C, and T49C, in Figure 9a1, b1, and b2, correspond to the distributions of the thermometers in Figure 3. In Figure 9b1, the coordinate of 


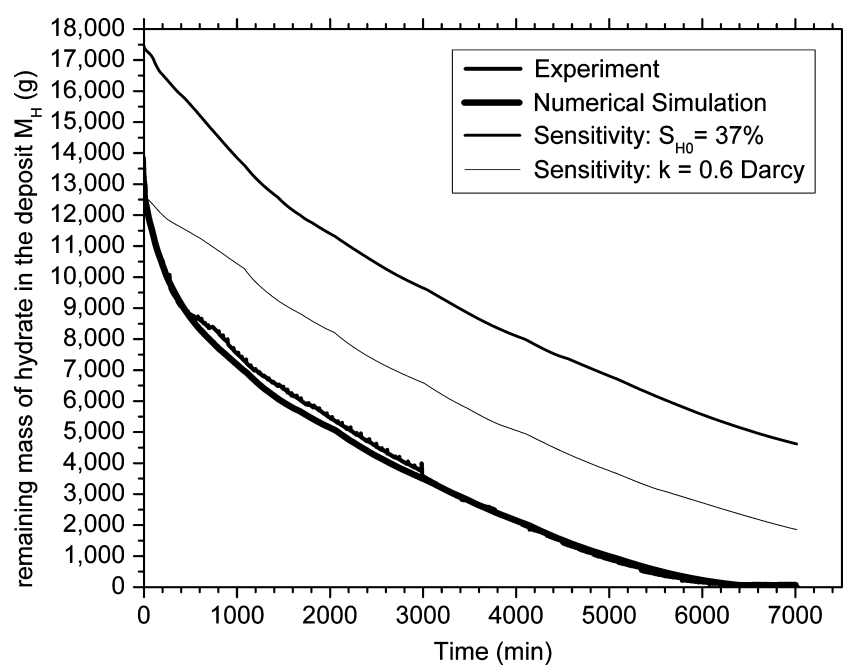

Figure 8. Comparison of the remaining mass of hydrate in the deposit $M_{\mathrm{H}}$ over time of experimental and numerical simulation results during hydrate dissociation in the PHS, and its sensitivities to $S_{\mathrm{H} 0}$ and $k$ of the numerical simulation.

T28A is $r=0.1768 \mathrm{~m}, z=0.15 \mathrm{~m}$, while that of T7A in Figure $9 \mathrm{~b} 2$ is $r=0.25 \mathrm{~m}, z=0.15 \mathrm{~m}$. The solid rectangle of T25A, T25C, T28C, and T28A in Figure 9b1 corresponds to that in Figure 9a1. The dashed rectangle of T25A, T25C, T7C, and T7A in Figure 9b2 corresponds to that in Figure 9a1.
According to the experimental results (Figures 9a1-a4), the temperatures of $\mathrm{T} 1, \mathrm{~T} 7, \mathrm{~T} 43$, and $\mathrm{T} 49$, the thermometers adjacent to the boundaries of the stainless steel of the PHS (Figure 4), increase obviously over time and are all slightly lower than the temperature of the boundaries $T_{\text {bon }}=5.98,6.71$, 7.09 , and $7.98{ }^{\circ} \mathrm{C}$ at $t=0,2500,3500$, and $5500 \mathrm{~min}$, respectively. The stainless steel boundaries of the PHS supply enough energy and heat from the surroundings for hydrate dissociation in the PHS.

The experimental and numerical simulation results in Figure 9 show (i) the fine agreements of the $T$ spatial distributions and their evolutions over time between numerical and experimental results; (ii) the evolution of the temperature gradient in the PHS over time; (iii) the temperature increase of the hydrate deposit over time, especially in the area near the stainless steel boundaries of the PHS; (iv) the limited temperature increase around the center $(r=0, z=0)$ of the PHS and the existence of the low- $\mathrm{T}$ area (defined as the area with $T<6.5{ }^{\circ} \mathrm{C}$ ). Of those, (ii) and (iii) are caused by the heat transfer from the boundaries with relative high temperature $T_{\text {bon }}$ (iv) is caused by the effect of the undissociated hydrate in the vicinity of the PHS center, and the energy transferred from the surroundings is used as the latent heat during the equilibrium reaction of hydrate dissociation.

We can see that the numerical results of the cumulative gas produced, the remaining mass of hydrate in the deposit over time, and the spatial distribution of the temperature over time in the PHS all agree well with the experiments, which
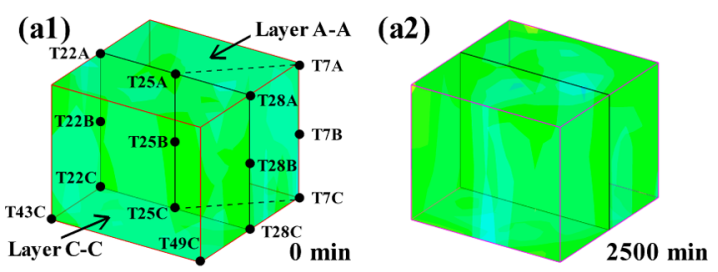

(a3)
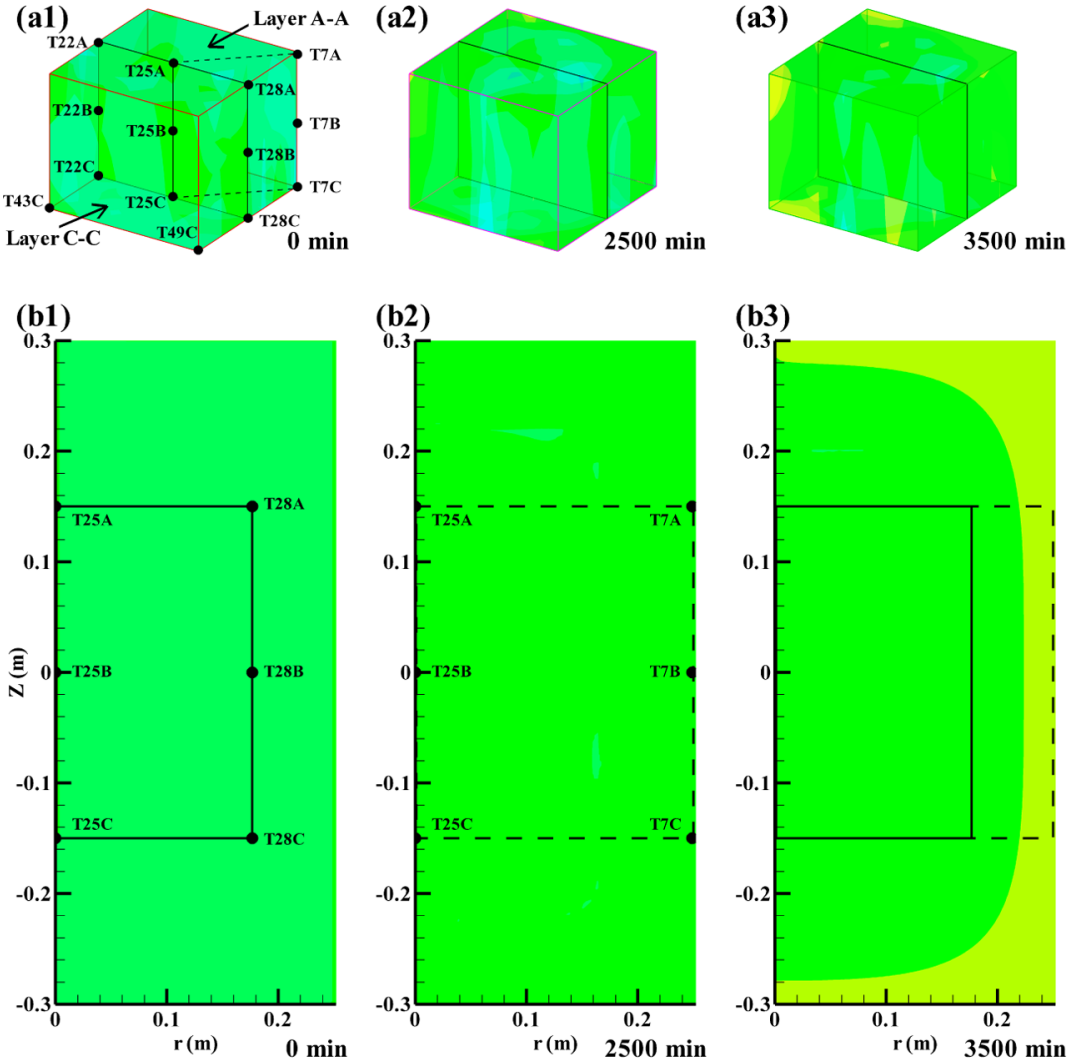

(b2)

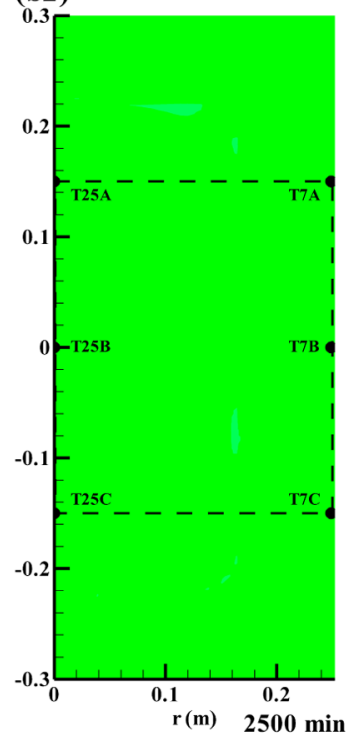

(b3)

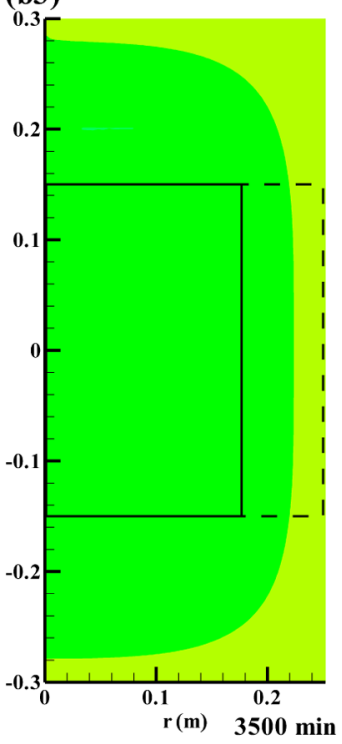

(a4)

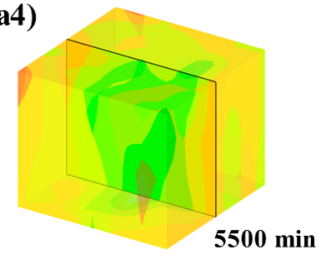

(b4)
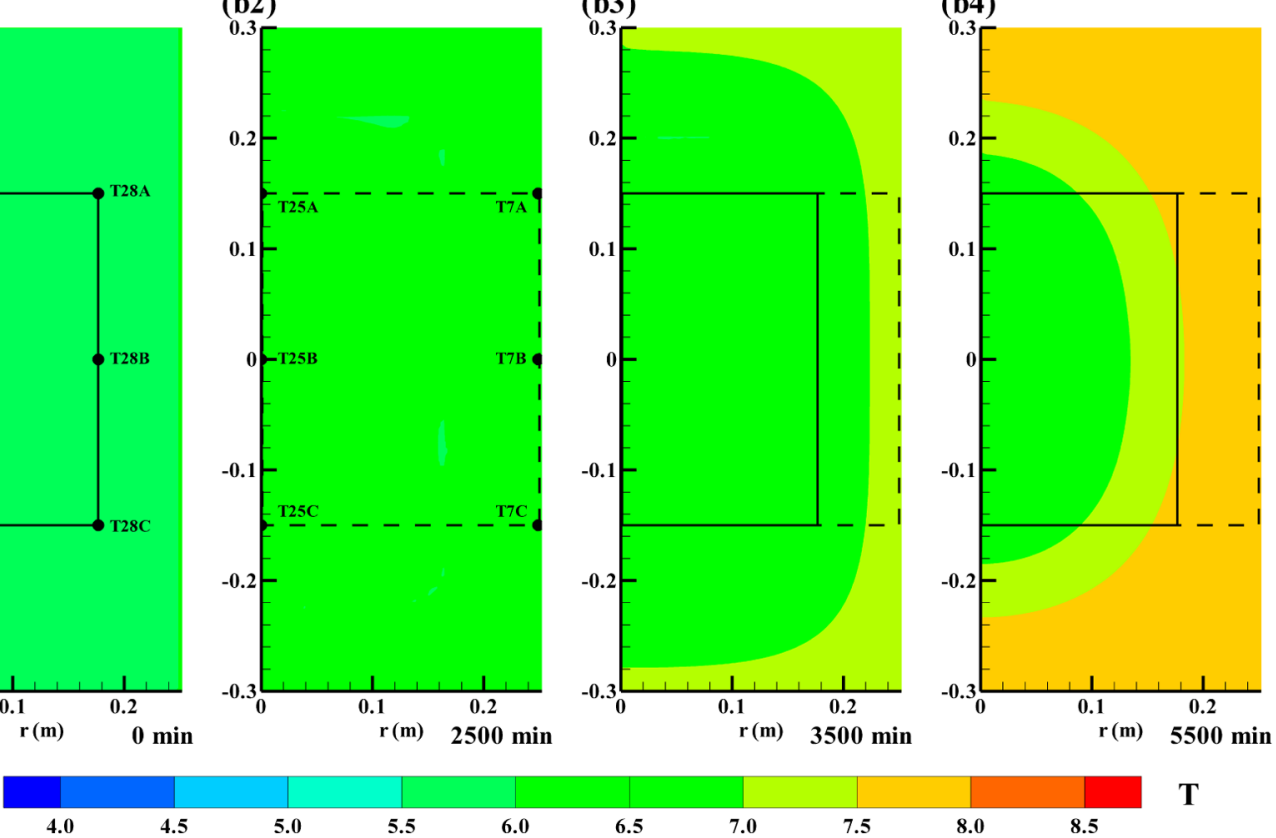

6.5

$\mathbf{T}$

Figure 9. Comparison of the spatial distributions of $T$ over time of experimental (a1-a4) and numerical simulation (b1-b4) results during hydrate dissociation in the PHS. 

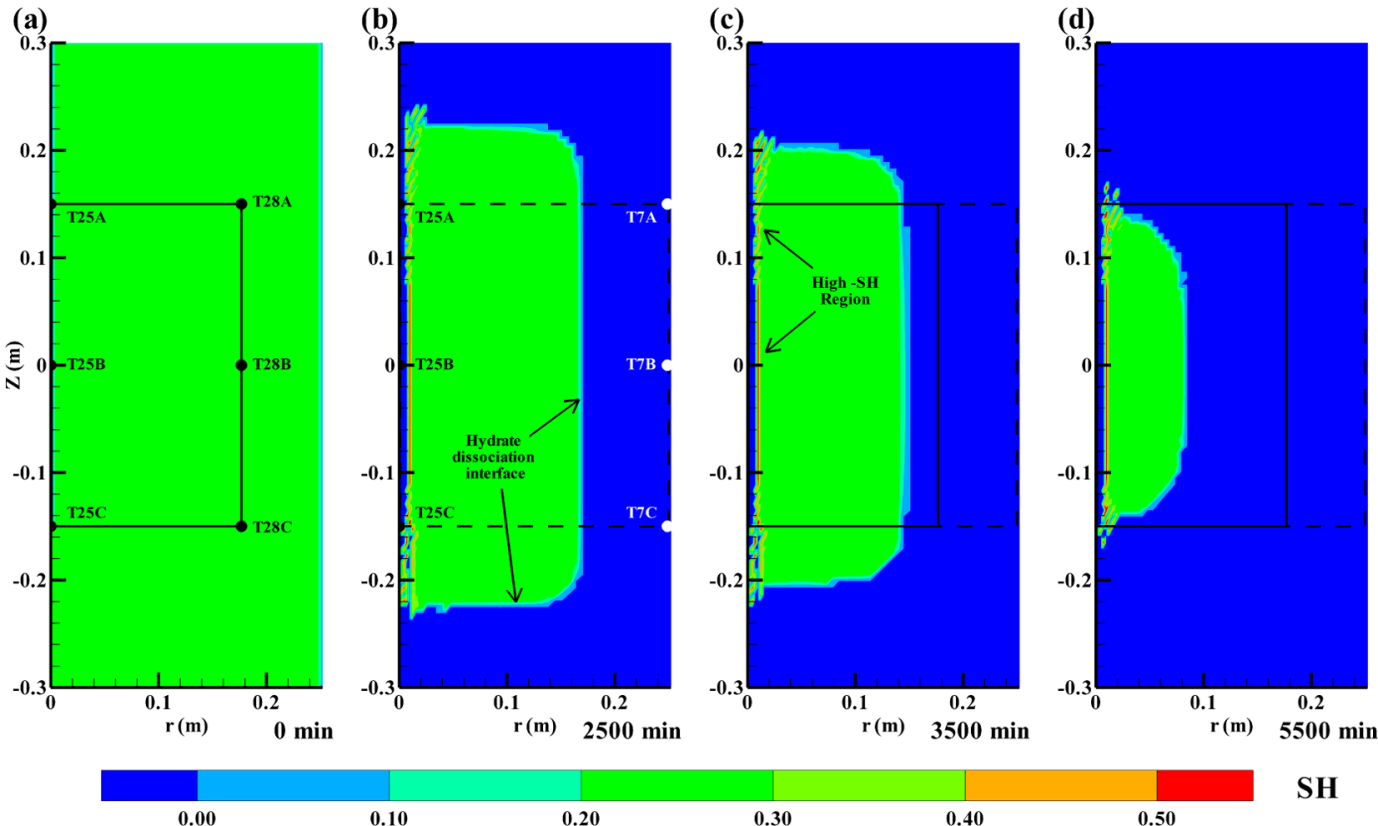

Figure 10. Evolution of spatial distribution of $S_{\mathrm{H}}$ over time of numerical simulation results during hydrate dissociation in the PHS.
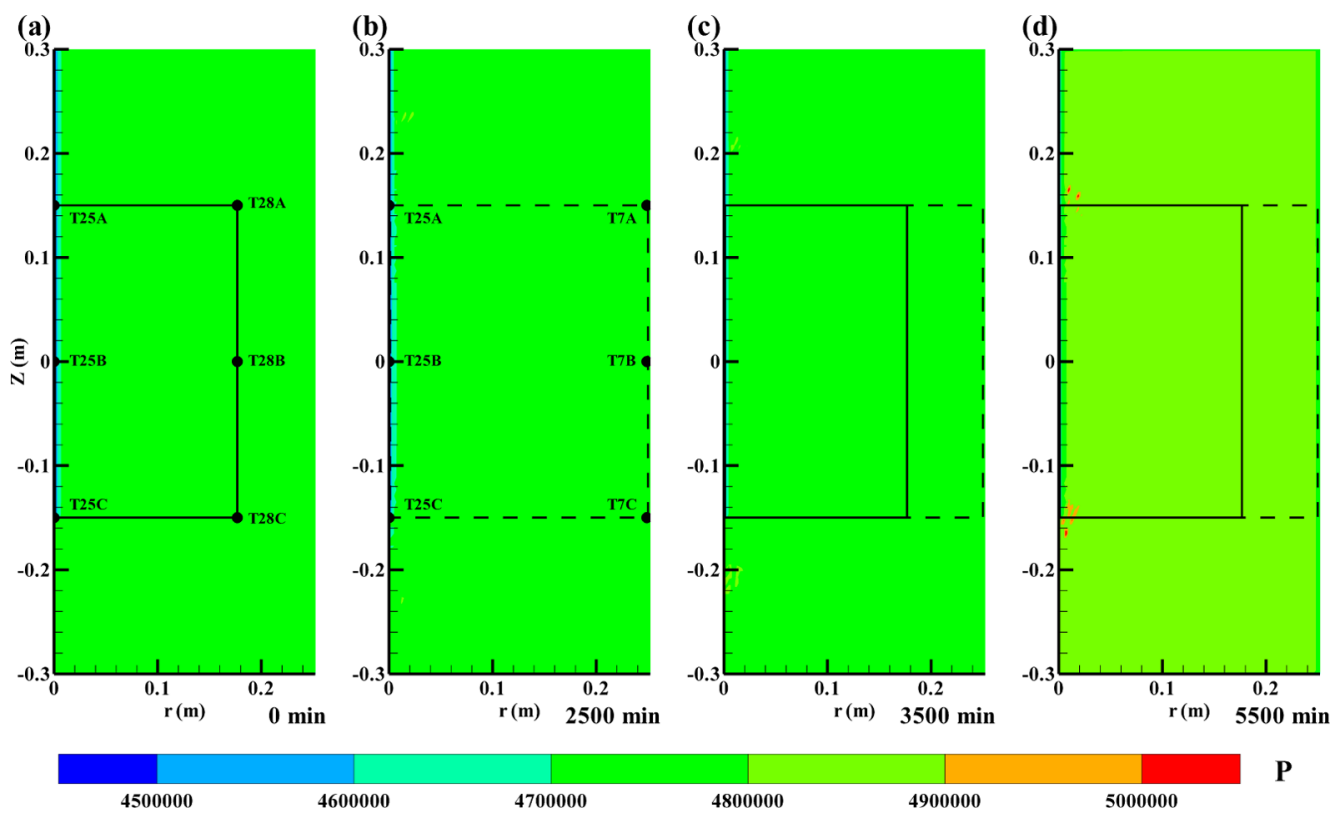

Figure 11. Evolution of spatial distribution of $P$ over time of numerical simulation results during hydrate dissociation in the PHS.

completes the validation of the mathematical model and numerical codes employed in this study.

4.4. Spatial Distribution of $S_{\mathrm{H}}$. Figure 10 shows the evolution of the spatial distribution of the hydrate saturation $S_{\mathrm{H}}$ over time of numerical simulation results during hydrate dissociation in the PHS. Considering the lack of the direct measurement of $S_{\mathrm{H}}$ in the PHS during the experimental investigation in this study, and the validation and the reliability of the numerical simulation results already confirmed in Figures 6-9, comparison of the spatial distributions of the hydrate saturation $S_{\mathrm{H}}$ over time with the initial PHS provides a measure of the hydrate dissociation profile.

The figure shows (i) the hydrate dissociation interface (Figure 10b), which separates the hydrate dissociated zone containing only gas and water from the undissociated zone (bounded by the dissociation interface) containing the hydrate; (ii) the evolution of the hydrate dissociation interface, which moves from the boundaries of the PHS toward the center; (iii) the correspondence between the hydrate undissociated zone and the low-T area in Figure 9; (iv) the decrease of the hydrate dissociation interface over time; $(\mathrm{v})$ the limited high- $S_{\mathrm{H}}$ region (Figure 10c, defined as the area with $S_{\mathrm{H}}$ larger than the initial hydrate saturation $S_{\mathrm{H} 0}=27 \%$, in Table 2 ) near the production well. Of those, (i) confirms the existence of the hydrate dissociation boundary, where gas and water are produced from hydrate, and indicates that the hydrate dissociation is an analog of a moving boundary ablation process; ${ }^{7,21,41}$ (ii) is caused by the temperature increase of $T_{\text {bon }}$ (Figure 5) and the heat transfer from the boundaries; (iii) indicates that the heat needed for the hydrate dissociation is equivalent to that 
supplied from the ambient, and the temperature of the hydrate undissociated zone basically maintains constant, while $T$ of the hydrate dissociated zone increases after hydrate dissociation (Figure 5); (iv) confirms the decreases of the hydrate dissociation rate and the gas and water production rates already discussed in Figures 6 to 8; (v) indicates the limitation of the secondary hydrate formation, which is the result of the constant pressure depressurization method under mild pressure drops.

4.5. Spatial Distribution of $\boldsymbol{P}$. Figure 11 shows the evolution of the spatial distribution of the system pressure $P$ over time of numerical simulation results during hydrate dissociation in the PHS. As already discussed above, the pressures at the different measuring points in the PHS have little discrepancy due to the high porosity and permeability of the sediment, and this hypothesis of the experiment is validated by the numerical simulation results shown in Figure 11. The pressure increases in the dissociated and undissociated zones in Figure $11 \mathrm{~d}$ are caused by the temperature increase in the PHS due to the heat transfer from the boundaries. Comparison of Figure $10 \mathrm{~d}$ and Figure $11 \mathrm{~d}$ obviously shows the exact correspondence between locations of the secondary hydrate formation and the relative high pressure area near the production well.

4.6. Sensitivity to $\boldsymbol{k}$. We investigate the sensitivity of the production performance to the intrinsic permeability $k$ and the initial hydrate saturation $S_{\mathrm{H} 0}$ of the numerical simulation. Figures 6-8 show respectively the dependences of the cumulative gas $V_{\mathrm{P}}$ and water $M_{\mathrm{W}}$ produced and the remaining mass of hydrate in the deposit $M_{\mathrm{H}}$ over time on $k$ and $S_{\mathrm{H} 0}$.

Figure 6 shows that reducing $k$ from 3.0 to 0.6 Darcy results in significant deterioration of gas production performance. The cumulative water produced $M_{\mathrm{W}}$ in Figure 7 also decreases with a decrease of $k$, and this shows a positive effect (limited water production rate during gas production from the hydrate reservoir) on the gas to water ratio during the gas production process. In the deposits with the intrinsic permeability of $0.6-$ 3.0 Darcy, the positive effect of the reduction of the water production is significant comparing with the adverse effect on the gas production potential. As seen in Figure 8, there is still hydrate undissociated in the deposit at the end of the production process in the lower $k$ case, with the remaining mass of hydrate in the deposit $M_{\mathrm{H}}$ of approximately $1860 \mathrm{~g}$.

4.7. Sensitivity to $S_{\mathrm{HO}}$. The initial hydrate and aqueous saturations before hydrate dissociation are $S_{\mathrm{H} 0}=27 \%$ and $S_{\mathrm{A} 0}=$ $37 \%$ (Table 2), respectively. By increasing $S_{\mathrm{H} 0}$ to $37 \%$, and meanwhile maintaining $S_{\mathrm{A} 0}$, the initial gas saturation $S_{\mathrm{G} 0}$ decreases from $36 \%$ to $26 \%$. As seen in Figure 6, a higher $S_{\mathrm{H} 0}$ results in a lower gas production rate, which is attributed to a combination of (a) the decrease of the effective permeability $k_{\text {eff }}$ in the deposit with high hydrate saturation and (b) the reduction of the gas saturation in the deposit. Of those, (a) is also the main reason for the decrease of $M_{\mathrm{W}}$ at the beginning of the production process in the higher $S_{\mathrm{H} 0}$ case (Figure 7). With the hydrate dissociation and the increase of $k_{\text {eff }}$ in the deposit, $M_{\mathrm{W}}$ in the case with a higher $S_{\mathrm{H} 0}$ and the same $S_{\mathrm{A} 0}$ is larger at the end of the production process.

In Figure 8, the initial mass of hydrate in the deposit of the numerical simulation results $\left(S_{\mathrm{H} 0}=27 \%\right)$ is approximately $M_{\mathrm{H}}$ $=12,730 \mathrm{~g}$, and the remaining mass of hydrate is $M_{\mathrm{H}}=0$ at the end of the production process $(t=7014 \mathrm{~min})$. In the higher $S_{\mathrm{H} 0}$ case, the initial mass of hydrate $M_{\mathrm{H}}=17450 \mathrm{~g}$, and $M_{\mathrm{H}}=4620$ $\mathrm{g}$ at $t=7014 \mathrm{~min}$, which means that approximately $12830 \mathrm{~g}$ hydrate dissociates during the production process in this case. This indicates that the initial hydrate saturation $S_{\mathrm{HO}}$ has little effect on the remaining mass of hydrate in this study, and the main reason for this is that the heat transfer from the ambient is the major control factor of the hydrate dissociation process, as discussed.

\section{CONCLUSIONS}

The following conclusions are drawn from both the experimental and the numerical simulation results:

(1) The hydrate dissociates continuously, and there is little hydrate remaining in the PHS at the end of the production process. The gas and water production rates and the hydrate dissociation rate decrease over time while using the constant-pressure depressurization method.

(2) The hydrate dissociation is an analog of a moving boundary ablation process in this study, and gas and water are produced from hydrate at the hydrate dissociation interface. With the temperature increase of $T_{\text {bon }}$ and the heat transfer from the boundaries, the hydrate dissociation interface moves from the boundaries of the PHS toward the center.

(3) Due to the heat transfer from the boundaries, the evolution of the temperature gradient and the temperature increase in the hydrate dissociated zone near the boundaries are observed. On the other hand, the temperature in the hydrate undissociated zone basically maintains constant, and the energy transferred from the surroundings is used as the latent heat during the equilibrium reaction of hydrate dissociation.

(4) The pressures at the different measuring points in the PHS have little discrepancy due to the high porosity and permeability of the sediment, and this hypothesis of the experiment is validated by the pressure spatial distribution of the numerical simulation results.

(5) The numerical results of the cumulative gas produced, the remaining mass of hydrate, and the spatial distribution of the temperature, all agree well with the experiments, which completes the validation of the mathematical model and numerical codes employed in this study. The heat transfer from the surroundings is predominant in our experimental and numerical cases.

(6) The analysis of sensitivity to $S_{\mathrm{H} 0}$ indicates that a higher $S_{\mathrm{H} 0}$ results in a lower gas production rate due to the decrease of the effective permeability $k_{\text {eff }}$ and the reduction of the gas saturation $S_{\mathrm{G} 0}$ in the deposit. Initial hydrate saturation $S_{\mathrm{H} 0}$ has little effect on the remaining mass of hydrate, and the main reason is that the heat transfer from the ambient is the major control factor of the hydrate dissociation process.

\section{AUTHOR INFORMATION}

\section{Corresponding Author}

*Tel./Fax: +86 20 87057037. E-mail: lixs@ms.giec.ac.cn.

\section{Notes}

The authors declare no competing financial interest.

\section{ACKNOWLEDGMENTS}

This work was supported by National Natural Science Foundation of China (Grant Nos. 51004089, 51076155, and 
51106160) and CAS Magnitude Arrangement Foundation (KGZD-EW-301-2), which are gratefully acknowledged.

\section{NOMENCLATURE}

$k=$ intrinsic permeability $\left(\mathrm{m}^{2}\right)$

$k_{\text {eff }}=$ effective permeability $\left(\mathrm{m}^{2}\right)$

$k_{\mathrm{rA}}=$ aqueous relative permeability $\left(\mathrm{m}^{2}\right)$

$k_{\mathrm{rG}}=$ gas relative permeability $\left(\mathrm{m}^{2}\right)$

$k_{\mathrm{\Theta RD}}=$ thermal conductivity of dry porous medium $(\mathrm{W} / \mathrm{m} /$ $\mathrm{K})$

$k_{\Theta \mathrm{RW}}=$ thermal conductivity of fully saturated porous medium $(\mathrm{W} / \mathrm{m} / \mathrm{K})$

$k_{\Theta \mathrm{I}}=$ thermal conductivity of ice $(\mathrm{W} / \mathrm{m} / \mathrm{K})$

$M_{\mathrm{H}}=$ remaining mass of hydrate in the deposit $(\mathrm{g})$

$M_{\mathrm{W}}=$ cumulative volume of the produced water (L)

$P=$ pressure $(\mathrm{MPa})$

$r, z=$ cylindrical coordinates $(\mathrm{m})$

$r_{\mathrm{W}}=$ well radius $(\mathrm{m})$

$S=$ phase saturation, volume

$T=$ temperature $\left({ }^{\circ} \mathrm{C}\right)$

$t=$ time $(\mathrm{min})$

$V_{\mathrm{P}}=$ cumulative volume of the gas produced $(\mathrm{L})$

$\phi=$ porosity

$\rho_{\mathrm{R}}=$ grain density $\left(\mathrm{kg} / \mathrm{m}^{3}\right)$

$\lambda=$ van Genuchten exponent - Table 2

$\Delta R=$ height of the PHS

$\Delta Z=$ diameter of the PHS

\section{Subcripts and Superscripts}

$0=$ denotes initial state

$\mathrm{A}=$ aqueous phase

Bon $=$ boundary

cap = capillary

$\mathrm{G}=$ gas phase

$\mathrm{H}=$ solid hydrate phase

$\mathrm{I}=$ ice phase

irA $=$ irreducible aqueous phase

irG = irreducible gas

$n=$ permeability reduction exponent, Table 2

$n_{\mathrm{G}}=$ gas permeability reduction exponent, Table 2

$\mathrm{R}=$ rock

$\mathrm{W}=$ well

\section{REFERENCES}

(1) Sloan, E. D.; Koh, C. A. Clathrate Hydrates of Natural Gases, 3rd ed.; CRC Press: Boca Raton, FL, 2008.

(2) Collett, T. S. Gas hydrates as a future energy resource. Geotimes 2004, 49 (11), 24-27.

(3) Moridis, G. J.; Collett, T. S.; Boswell, R.; Kurihara, M.; Reagan, M. T.; Koh, C.; Sloan, E. D. Toward production from gas hydrates: Current status, assessment of resources, and simulation-based evaluation of technology and potential. SPE Reservoir Eval. Eng. 2009, 12 (5), 745-771.

(4) Moridis, G. J.; Collett, T. S.; Pooladi-Darvish, M.; Hancock, S.; Santamarina, C.; Boswell, R.; Kneafsey, T.; Rutqvist, J.; Kowalsky, M. B.; Reagan, M. T.; Sloan, E. D.; Sum, A. K.; Koh, C. A. Challenges, uncertainties, and issues facing gas production from gas-hydrate deposits. SPE Reservoir Eval. Eng. 2011, 14 (1), 76-112.

(5) Makogon, Y. F.; Holditch, S. A.; Makogon, T. Y. Natural gashydrates-A potential energy source for the 21 st century. J. Pet. Sci. Eng. 2007, 56 (1-3), 14-31.

(6) Holder, G. D.; Angert, P. F.; Godbole, S. P. Simulation of gas production from a reservoir containing both gas hydrates and free natural gas. In 1982 SPE Annual Technical Conference and Exhibition, New Orleans, LA, 1982.
(7) Yousif, M. H.; Abass, H. H.; Selim, M. S.; Sloan, E. D. Experimental and theoretical investigation of methane-gas-hydrate dissociation in porous media. SPE Reservoir Eng. 1991, 6 (4), 69-76.

(8) Moridis, G. J.; Kowalsky, M. B. Depressurization-induced gas production from Class 1 and Class 2 hydrate deposits. In TOUGH Symposium; Lawrence Berkeley National Laboratory: Berkeley, CA, 2006.

(9) Li, G.; Moridis, G. J.; Zhang, K.; Li, X. S. Evaluation of gas production potential from marine gas hydrate deposits in Shenhu area of South China Sea. Energy Fuels 2010, 24 (11), 6018-6033.

(10) Li, G.; Li, X. S.; Chen, Q.; Chen, Z. Y. Numerical simulation of gas production from gas hydrate zone in Shenhu area, South China Sea. Acta Chim. Sin. 2010, 68 (11), 1083-1092.

(11) Kamath, W. A.; Godbole, S. R. Evaluation of hot-brine stimulation technique for gas production from natural gas hydrates. J. Pet. Technol. 1987, 39 (11), 1379-1388.

(12) Li, G.; Tang, L. G.; Huang, C.; Feng, Z. P.; Fan, S. S. Thermodynamic evaluation of hot brine stimulation for natural gas hydrate dissociation. J. Chem. Ind. Eng. (China) 2006, 57 (9), 20332038.

(13) Li, G.; Li, X. S.; Tang, L. G.; Li, Q. P. Control mechanisms for methane hydrate production by thermal stimulation. In The 6th International Conference on Gas Hydrates, Vancouver, British Columbia, Canada, 2008; Paper 5783.

(14) Kawamura, T.; Ohtake, M.; Sakamoto, Y.; Yamamoto, Y.; Haneda, H.; Komai, T.; Higuchi, S. Experimental study on steam injection method using methane hydrate core samples. In The 7th ISOPE Ocean Mining Symposium, Lisbon, Portugal, 2007.

(15) Kawamura, T.; Sakamoto, Y.; Ohtake, M.; Yamamoto, Y.; Haneda, H.; Yoon, J. H.; Komai, T. Dissociation behavior of hydrate core sample using thermodynamic inhibitor. In The 15th International Offshore and Polar Engineering Conference, Seoul, South Korea, 2005; pp 5-9.

(16) Li, G.; Li, X. S.; Tang, L. G.; Zhang, Y. Experimental investigation of production behavior of methane hydrate under ethylene glycol injection in unconsolidated sediment. Energy Fuels 2007, 21 (6), 3388-3393.

(17) Lee, J. Experimental study on the dissociation behavior and productivity of gas hydrate by brine injection scheme in porous rock. Energy Fuels 2010, 24 (1), 456-463.

(18) Li, G.; Moridis, G. J.; Zhang, K.; Li, X. S. The use of huff and puff method in a single horizontal well in gas production from marine gas hydrate deposits in the Shenhu Area of South China Sea. J. Pet. Sci. Eng. 2011, 77 (1), 49-68.

(19) Li, G.; Li, X. S.; Wang, Y.; Zhang, Y. Production behavior of methane hydrate in porous media using huff and puff method in a novel three-dimensional simulator. Energy 2011, 36 (5), 3170-3178.

(20) Moridis, G. J.; Reagan, M. T.; Kim, S. J.; Seol, Y.; Zhang, K. Evaluation of the gas production potential of marine hydrate deposits in the Ulleung Basin of the Korean East Sea. SPE J. 2009, 14 (4), 759781.

(21) Makogon, Y. F. Hydrates of Hydrocarbons; Penn Well: Tulsa, OK, 1997.

(22) Burshears, M.; O’Brien, T. J.; Malone, R. D. A multi-phase multi-dimensional, variable composition simulation of gas production from a conventional gas reservoir in contact with hydrates. In The SPE Unconventional Gas Technology Symposium, Louisville, Kentucky, 1986; pp 18-21.

(23) Kim, H. C.; Bishnoi, P. R.; Heidemann, R. A.; Rivzi, S. S. H. Kinetics of methane hydrate decomposition. Chem. Eng. Sci. 1987, 42 (7), 1645-1653.

(24) Tsypkin, G. G. Regimes of dissociation of gas hydrates coexisting with a gas in natural strata. J. Eng. Phys. Thermophys. 2001, 74 (5), 1083-1089.

(25) Ahmadi, G.; Ji, C.; Smith, D. H. Numerical solution for natural gas production from methane hydrate dissociation. J. Pet. Sci. Eng. 2004, 41 (4), 269-285. 
(26) Ahmadi, G.; Ji, C.; Smith, D. H. Natural gas production from hydrate dissociation: An axisymmetric model. J. Pet. Sci. Eng. 2007, 58 (1-2), 245-258.

(27) Ji, C.; Ahmadi, G.; Smith, D. H. Natural gas production from hydrate decomposition by depressurization. Chem. Eng. Sci. 2001, 56 (20), 5801-5814.

(28) Sun, X.; Nanchary, N.; Mohanty, K. K. 1-D modeling of hydrate depressurization in porous media. Transp. Porous Media 2005, 58 (3), 315-338.

(29) Lee, J.; Park, S.; Sung, W. An experimental study on the productivity of dissociated gas from gas hydrate by depressurization scheme. Energy Convers. Manage. 2010, 51 (12), 2510-2515.

(30) Tang, L. G.; Li, X. S.; Feng, Z. P.; Li, G.; Fan, S. S. Control mechanisms for gas hydrate production by depressurization in different scale hydrate reservoirs. Energy Fuels 2007, 21 (1), 227-233.

(31) Oyama, H.; Konno, Y.; Masuda, Y.; Narita, H. Dependence of depressurization-induced dissociation of methane hydrate bearing laboratory cores on heat transfer. Energy Fuels 2009, 23 (10), 49955002.

(32) Haligva, C.; Linga, P.; Ripmeester, J. A.; Englezos, P. Recovery of methane from a variable-volume bed of silica sand/hydrate by depressurization. Energy Fuels 2010, 24 (5), 2947-2955.

(33) Zhou, Y.; Castaldi, M. J.; Yegulalp, T. M. Experimental investigation of methane gas production from methane hydrate. Ind. Eng. Chem. Res. 2009, 48 (6), 3142-3149.

(34) Li, X. S.; Wang, Y.; Li, G.; Zhang, Y.; Chen, Z. Y. Experimental Investigation into methane hydrate decomposition during threedimensional thermal huff and puff. Energy Fuels 2011, 25 (4), 16501658.

(35) Li, X. S.; Zhang, Y.; Li, G.; Chen, Z. Y.; Wu, H. J. Experimental investigation into the production behavior of methane hydrate in porous sediment by depressurization with a novel three-dimensional cubic hydrate simulator. Energy Fuels 2011, 25 (10), 4497-4505.

(36) Li, X. S.; Yang, B.; Li, G.; Li, B.; Zhang, Y.; Chen, Z. Y. Experimental study on gas production from methane hydrate in porous media by huff and puff method in Pilot-Scale Hydrate Simulator. Fuel 2012, 94 (1), 486-494.

(37) Li, X. S.; Zhang, Y.; Li, G.; Chen, Z. Y.; Yan, K. F.; Li, Q. P. Gas hydrate equilibrium dissociation conditions in porous media using two thermodynamic approaches. J. Chem. Thermodyn. 2008, 40 (9), 14641474.

(38) Moridis, G. J.; Kowalsky, M. B.; Pruess, K. TOUGH+HYDRATE v1.1 User's Manual: A Code for the Simulation of System Behavior in Hydrate-Bearing Geologic Media; Lawrence Berkeley National laboratory: Berkeley, CA, 2009.

(39) Zhang, K.; Moridis, G. J.; Wu, Y. S.; Pruess, K. A domain decomposition approach for large-scale simulations of flow processes in hydrate-bearing geologic media. In The 6th International Conference on Gas Hydrates, Vancouver, British Columbia, Canada, 2008; Paper 5480 .

(40) Kowalsky, M. B.; Moridis, G. J. Comparison of kinetic and equilibrium reaction models in simulating gas hydrate behavior in porous media. Energy Convers. Manage. 2007, 48 (6), 1850-1863.

(41) Selim, M. S.; Sloan, E. D. Hydrate dissociation in sediment. SPE Reservoir Eng. 1990, 5 (2), 245-251.

(42) Moridis, G. J.; Seol, Y.; Kneafsey, T. J. Studies of reaction kinetics of methane hydrate dissociation in porous media. In The 5th International Conference on Gas Hydrate, Trondheim, Norway, 2005; pp 1004-1014.

(43) van Genuchten, M. T. A closed-form equation for predicting the hydraulic conductivity of unsaturated soils. Soil Sci. Soc. Am. J. 1980, 44, 892-898. 